\title{
Optical Interconnect Waveguide in Electronic Circuit
}

\author{
Siti Sarah Binti Md Sallah ${ }^{1}$, Sawal Hamid Md Ali ${ }^{2}$, Nurjuliana Binti Juhari ${ }^{3}$, P. Sushitha Menon ${ }^{4}$, \\ Md Shabiul Islam ${ }^{5}$ \\ ${ }^{1,2}$ Faculty of Engineering and Build Environment (FKAB), Universiti Kebangsaan Malaysia, Malaysia \\ ${ }^{3}$ School of Microelectronic Engineering, Universiti Malaysia Perlis, Malaysia \\ ${ }^{4}$ Institute of Microengineering and Nanoelectronics (IMEN), Universiti Kebangsaan Malaysia \\ ${ }^{5}$ Faculty of Engineering, Multimedia University (Cyberjaya), Malaysia
}

\section{Article Info \\ Article history: \\ Received Aug 4, 2016 \\ Revised Oct 19, 2016 \\ Accepted Nov 2, 2016 \\ Keyword: \\ Electrical interconnect Optical interconnect Optical waveguide Two-stage CE amplifier}

\begin{abstract}
The increasing demand in silicon nano-photonics has encouraged many researchers to put more efforts to explore the feasibility of using optics in the communication medium in order to replace the conventional electrical interconnects (EIs). In this paper, we proposed a SOI- based waveguide in the optical interconnect (OI) link at an operating frequency of $1550 \mathrm{~nm}$ to work as an interconnection path in a circuit. The performance capability of the OI link was tested using a two-stage CE amplifier to work as the interconnection path from the 1 st stage to the 2 nd stage amplifier. In term of optical performances, the optical waveguide interconnect managed to achieve a single mode condition for a TE mode and fulfill the receiver sensitivity of a photodiode. While, in term of electrical performance, a two-stage CE amplifier is able to produce a high gain, a wide bandwidth and high slew rate. The proposed implementation of the OIs waveguide is succesfully enhance the performance of the two-stage CE amplifier as well as the analog electronic circuit applications.
\end{abstract}

Copyright $@ 2016$ Institute of Advanced Engineering and Science. All rights reserved.

\section{Corresponding Author:}

Siti Sarah Binti Md Sallah, Sawal Hamid Md Ali,

Faculty of Engineering and Build Environment (FKAB),

Universiti Kebangsaan Malaysia,

Bangi-43600, Selangor, Malaysia.

Email: sitisarah.mdsallah@gmail.com,sawal@ukm.edu.my

\section{INTRODUCTION}

Interconnects in the integrated circuit (IC) are used to connect transistors and other electronic components on a chip [1]. The performance of the conventional copper interconnects degrades substantially due to the scaling dimensions in the Complementrary Metal Oxide Semiconductor (CMOS) technology [2]. According to International Technology Roadmaps for Semiconductor (ITRS), the circuits to be manufactured in the nanometer scale will contain more than a billion transistors [3] and causing the requirement of large number of interconnects [4]. Therefore, the optical interconnects (OIs) have been considered as an alternative solution for the electrical interconnects (EIs) [5]. Moreover, silicon nano-photonics is a key technology for realizing that such optical components can be fabricated with Si CMOS compatible device processes [6]. The advantage of OI link compared to EIs is able to provide a high bandwidth density, minimizing lower power consumption, as well as decreasing interconnect delays and noise [7-11].

The theory of OI was introduced by Goodman in 1984 [12]. Figure 1 shows the basic block diagram of OI link on a very large scale integrated (VLSI) electronic circuit. The main components of OI are off- chip $\mathrm{CW}$ source, modulator, an optical waveguide and a photodetector. The most famous waveguide material are Polymer [13], Silicon-on-Insulator (SOI) [14] and Indium Gallium Arsenide Phosphide (InGaAsP). The applications of OI technology are in the computer system, mobile devices, as well as other electronic circuit systems. 


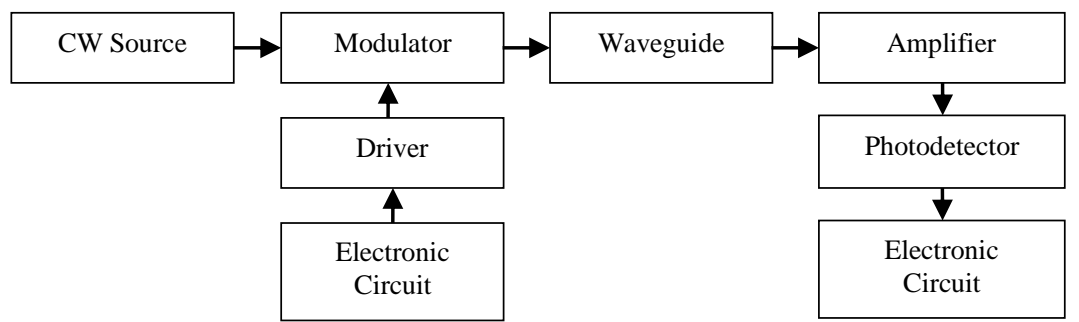

Figure 1. Block Diagram of OI link [12]

In this work, the SOI-based waveguide is implemented on the OI link with high-speed frequency of $1550 \mathrm{~nm}$ wavelength. This paper aims to evaluate both the electrical and optical performance of each device involved in the OI link. The electrical performance can be measured in an electrical part such as an electronic circuit; a two-stage CE amplifier. Meanwhile, optical performances can be measured in the optical parts such as the $\mathrm{CW}$ source, modulator, optical waveguide and photodetector.

\section{RESEARCH METHOD}

There are two simulation steps in this methodology; first, is the simulation of SOI waveguide and the second step is the implementation of the SOI waveguide in the OI link using a two-stage CE amplifier circuit.

\subsection{Simulation of the OI Waveguide}

A simple expression of a large rib waveguide to produce the SMC output is introduced by Soref et.al. [15] [16] in order to obtain a low propagation loss and delay. The expression is as follows:

$$
\begin{aligned}
& \frac{W}{H} \leq 0.3+\frac{r}{\sqrt{1-(r)^{2}}} \\
& \text { For } \quad 0.5 \leq r \leq 1
\end{aligned}
$$

Where $\mathrm{r}$ is the ratio of a slab height to the overall rib height, and $\mathrm{W} / \mathrm{H}$ is the ratio of a waveguide to the overall rib height. The analysis of the waveguides in Equation (1) is limited to the shallow etched ribs as per Equation (2). Figure 2 (a) presents a layout cross section of a large rib waveguide and (b) presents a SMC output of the SOI waveguide.

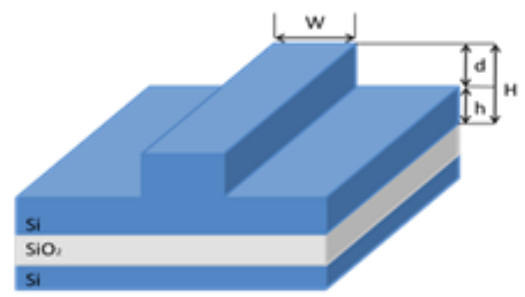

(a)

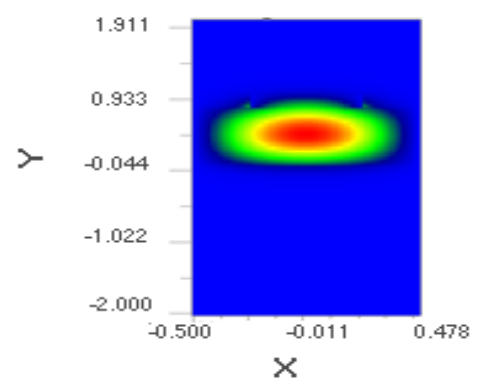

(b)

Figure 2. (a) Layout Cross Section of SOI Waveguide and (b) SMC Output of SOI Waveguide

The SOI waveguide was designed and simulated in an OptiBPM version 9. The material of the waveguide core was silicon $(\mathrm{Si})$ with a refractive index, $n \mathrm{Si}=3.477$, while the waveguide substrate was silicon dioxide $(\mathrm{SiO} 2)$ with $n \mathrm{SiO} 2=1.444$. Therefore, the effective index (neff) produced from this SOI waveguide was 3.308 [17]. 


\subsection{OI Link}

Figure 3 shows the schematic circuit of the two-stage CE amplifier with the implementation of SOI waveguide in the OI link. The length of the optical waveguide was set to $10000 \mu \mathrm{m}$. Referring to Figure 3 , the electrical signal from the 1st stage amplifier output was converted to an optical signal using a Mach-Zehnder modulator and was transmitted in an optical signal through the optical waveguide. Then the photodetector detected the signal and was converted back to the electrical signal. Therefore, the electrical signal is the input of the 1st stage amplifier and the output signal of 2 nd stage amplifier.

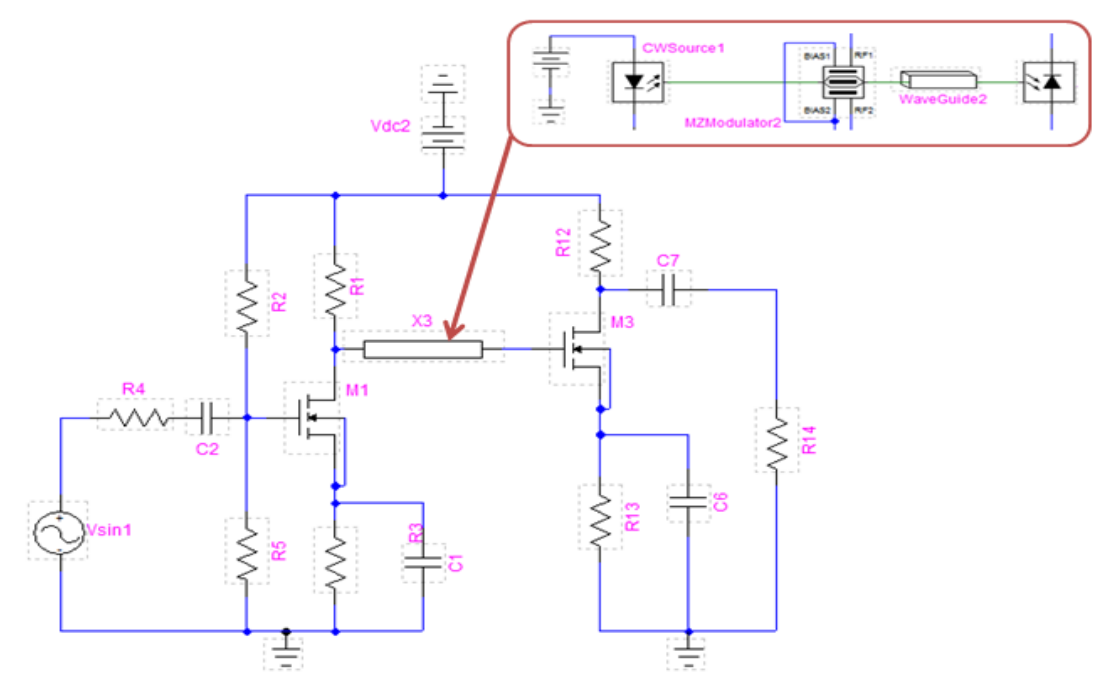

Figure 3. Integration of OI Link in the Two-Stage CE Amplifier

\section{RESULTS AND ANALYSIS}

The implementation of the OI link in the two-stage CE amplifier has been designed and simulated using the SPICE tool. During the analysis, the optical performance was measured at the optical component, while the electrical performance was measured at the electronic component, respectively.

\subsection{Optical Performances}

The optical performance measured was the line bandwidth of the spectrum profile, power loss and delay in the optical waveguide, power degradation in OI link, and receiver sensitivity of the photodetector. The frequency wavelength was set to $1550 \mathrm{~nm}$ and data bit rates were equal to $10 \mathrm{Gbps}$.

\subsubsection{Line Bandwidth of the Spectrum Profile}

Figures 4 (a) and (b) show the spectrum profile of the CW source and modulator with three different levels, $-3 \mathrm{~dB},-10 \mathrm{~dB}$, and $-20 \mathrm{~dB}$ level.

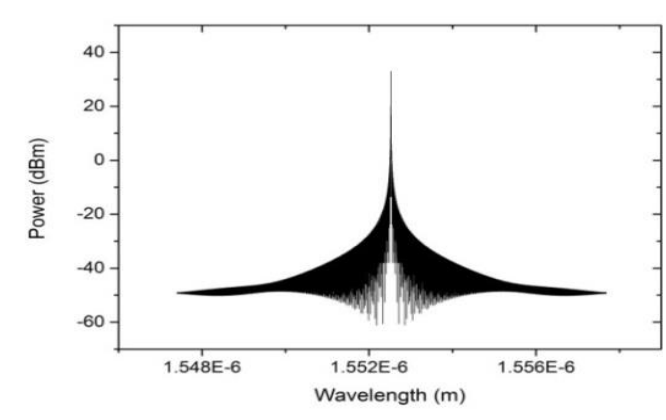

(a)

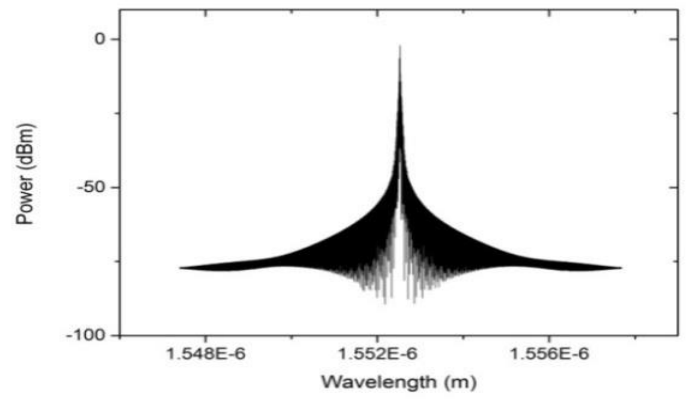

(b)

Figure 4. (a) CW Source Spectrum Profile and (b) MZ Modulator Spectrum Profile 
The line bandwidth for the $\mathrm{CW}$ source and MZ modulator was tabulated in Table 1. It can be seen that the modulated signal from the $\mathrm{MZ}$ modulator has a wider line width for all levels compared to the CW Source.

Table 1. The Performance of Line Bwidth for CW Source and MZ Modulator

\begin{tabular}{cccc}
\hline Component & -3dB level & $\begin{array}{c}\text { Line Width(nm) } \\
\text {-10dB level }\end{array}$ & -20dB level \\
\hline CW Source & 0.0004 & 0.002 & 0.008 \\
MZ modulator & 0.0008 & 0.019 & 0.4 \\
\hline
\end{tabular}

\subsubsection{Power loss in the Optical Waveguide and Power Degradation in the OI Link}

The power loss of the modulator and optical waveguide can be calculated via Equation (3) and (4):

$$
\begin{aligned}
& P_{\text {loss }(\bmod )}=P_{\bmod (\text { output })}-P_{C W(\text { output })} \\
& P_{\text {loss }(\text { waveguid } \phi}=P_{\text {waveguid(loutput })}-P_{\bmod (\text { output })}
\end{aligned}
$$

Figure 5 shows the power degradation of the OI link. The output power for CW Source was $34.034 \mathrm{dBm}$, MZ modulator was $2.952 \mathrm{dBm}$, SOI waveguide was $0.820 \mathrm{dBm}$ and PIN photodetector was $19.857 \mathrm{dBm}$. Therefore, the total power loss using SOI waveguide was $2.132 \mathrm{dBm}$.

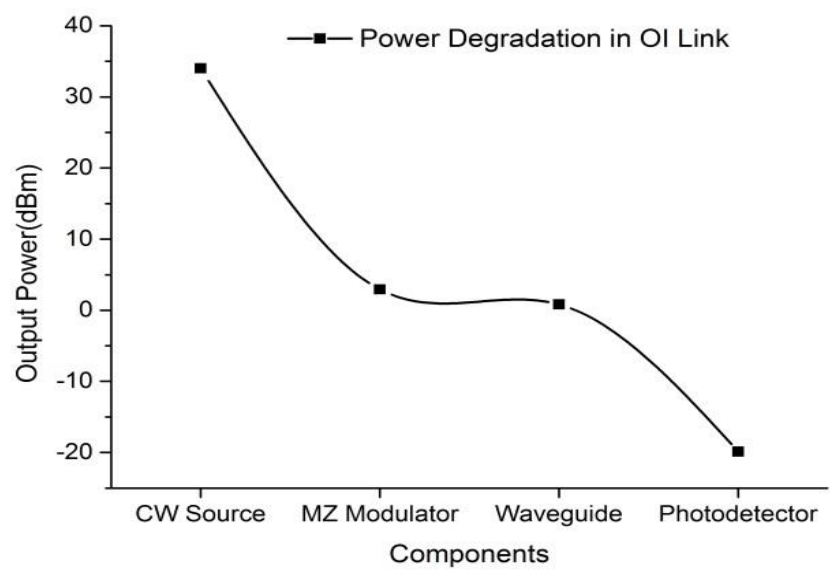

Figure 5. Power Degradation in OI link

\subsubsection{Delay in Optical Waveguide}

The output delay through the optical waveguide is expressed via Equation (5):

$$
t_{w g}=n_{e f f} \frac{L}{c}
$$

where neff is the effective index of the mode in the waveguide medium, $\mathrm{L}$ is the length of the waveguide and $\mathrm{c}$ is the speed of light in vacuum. For $\mathrm{r}$ is equal to $0.5 \mu \mathrm{m}$, the delay is $10.8 \mathrm{ps}$ [18].

\subsubsection{Receiver Sensitivity of the Photodetector}

The photodetector used is a PIN photodiode which can execute high bandwidth and sensitivity. For a photodiode material, Ge is more suitable due to a high speed for a short distance communication and lower cost. A $-19.857 \mathrm{dBm}$ of power sensitivity is produced in the simulation. 


\subsection{Electrical Performances}

The electrical performance measured was transient analysis, gain, frequency bandwidth, slew rate and propagation delay.

\subsubsection{Transient Analysis}

Figure 6 (a) and (b) show the input and output signals of the two-stage CE amplifier using OI. The input signal of the two- stage CE amplifier using OI was set to $12.5 \mathrm{mV}$-peak, while the output signal swung roughly at $4.52 \mathrm{~V}$-peak.

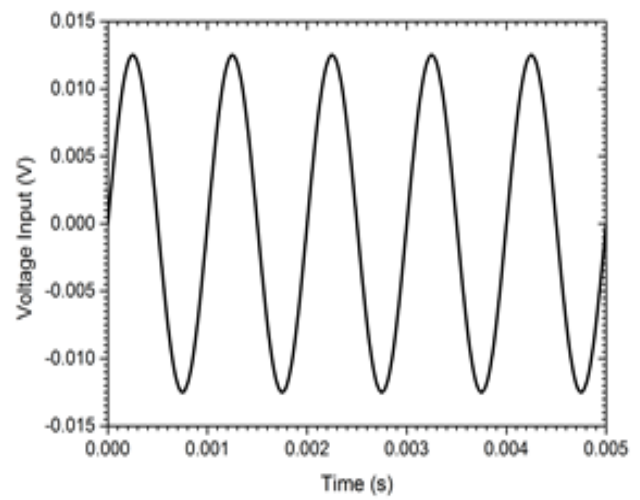

(a)

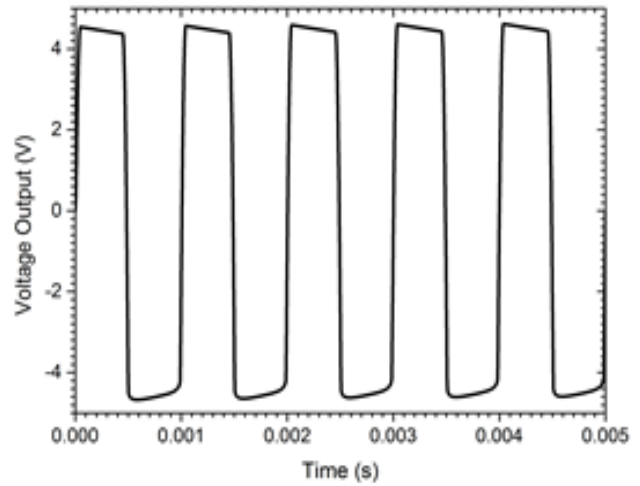

(b)

Figure 6. (a) Transient Input and (b) Transient Output of the Two-Stage CE Amplifier using OI

\subsubsection{Gain}

Gain of the amplifier refers to the ratio of output voltage to the input voltage. It represents how much an amplifier can amplify a given signal. Gain can be simply expressed in terms of a dimensionless quantity or in decibel (dB). Gains are calculated via Equation (6):

$$
G=\frac{V_{\text {out }}}{V_{\text {in }}}
$$

In $\mathrm{dB}$, the voltage gain is expressed by Equation (7):

$$
A_{v}(d B)=20 \log \frac{V_{\text {out }}}{V_{\text {in }}}
$$
respectively.

Using Equations (6) and (7), the gain of the two- stage CE amplifier using OI was 51.16 and 54.5,

\subsubsection{Frequency Bandwidth}

The bandwidth $(B W)$ of the amplifier represents the range of the frequency that amplifier can amplify effectively. The bandwidth of an amplifier is the difference between the lower half point, $f_{L}$ and upper half point, $f_{H}$ known as the frequency limits of an amplifier. The bandwidth is given via Equation (8):

$$
\text { Bandwidth(kB) }=f_{H}-f_{L}
$$


Figure 7 shows the frequency response of the two- stage CE amplifier. The $-3 \mathrm{~dB}$ points on a frequency response curve tagged $\mathrm{P} 1$ and $\mathrm{P} 2$ were the $f_{L}$ and $f_{H}$ respectively. Based on Figure 7 , the $f_{L}$ was $130 \mathrm{~Hz}$, whereas the $f_{H}$ was $80 \mathrm{kHz}$. Therefore, the $B W$ was $79.8 \mathrm{kHz}$.

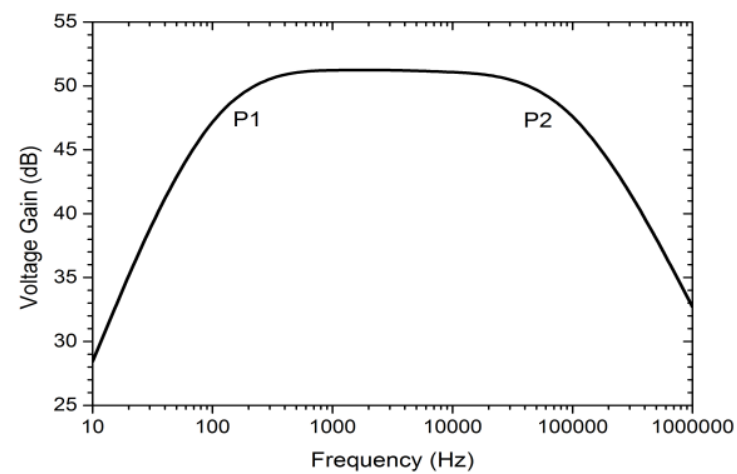

Figure 7. Frequency Bandwidth of Two-Stage CE Amplifier

\subsubsection{Slew Rate}

Slew rate, $S R$ of an amplifier is defined as the maximum rate of a change output voltage per unit of time. It represents how rapidly the output of an amplifier can be changed in response to the change in the input. The slew rate of the amplifier can be calculated using Equation (9):

$$
S R=\frac{\Delta V_{\text {out }}}{\Delta t}
$$

where $\Delta V_{\text {out }}$ is $V_{\max }-\left(-V_{\max }\right)$ and the units are in $\mathrm{V} / \mu \mathrm{s}$. The higher the value of the slew rate, the faster the output can change and more easily reproduce high frequency signals. Using Equation (9), the $S R$ of the twostage CE amplifier using OI was $24 \mathrm{~V} / \mu \mathrm{s}$.

\subsubsection{Propagation Delay for Different Interconnect Length}

Figure 8 presents a performance analysis of the OIs for the varying interconnects length. The propagation delay was analyzed from the output pin of the amplifier to the input pin of the next amplifier. The length value, on the other hand, was identified based on the optical waveguide length.

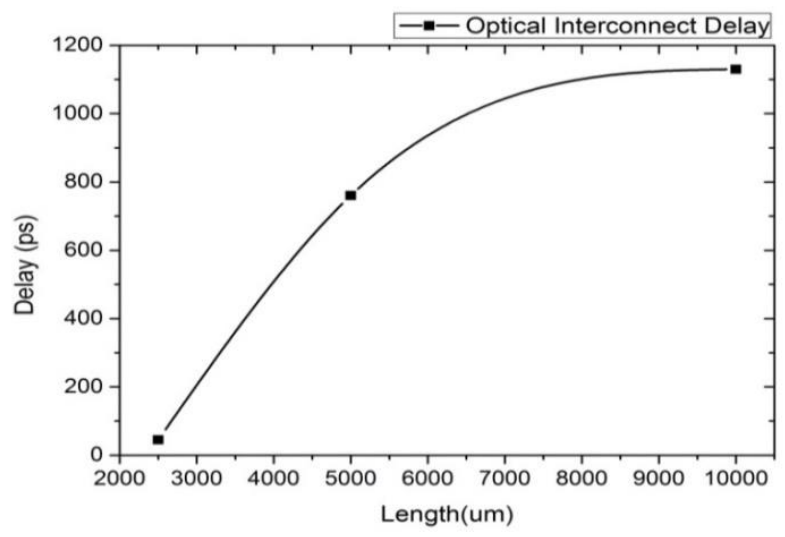

Figure 8. Propagation Delay of the Two-Stage CE Amplifier 


\section{CONCLUSION}

The integration of OI link in the analog electronic circuit was successfully performed by combining the electrical and optical components in the SPICE tools. The results were discussed from the viewpoint of the optical and electrical performances of the two-stage CE amplifier using OI. From the analysis, the used of SOI waveguide in OI the link produces high gain, bandwidth, slew rate and lower delay of the two-stage CE amplifier circuit. It is concluded that the SOI-based OI waveguide is a prominent solution for the short distance applications and one of the best solutions for the future VLSI interconnects.

\section{ACKNOWLEDGEMENTS}

The authors are grateful UKM and IMEN for useful discussions, supports, and the encouragement given for completing this research and funding is supported by grant DPP-2015-059.

\section{REFERENCES}

[1] M.G. Kumar, Y. Agrawal, and R. Chandel. Carbon Nanotube Interconnects - A Promising Solution for VLSI Circuits. IETE Journal of Education. 2016; 57(2): 46-6.

[2] J.H. Collet, F. Caignet, F. Sellaye, and D. Litaize. Performance Constraints for Onchip Optical Interconnects. IEEE Journal of Selected Topics in Quantum Electronics. 2013; 9: 425-432.

[3] D. Dunggal, G. Singh and M. Kaur. A Unified Codex Scheme for Reduction of Area and Crossstalk in RC and RLC Modeled Interconnects using both Bus Encoding and Shielding Insertion Technique. International Journal of Eectrical and Computer Engineering (IJECE). 2013; 3(4): 542-532.

[4] D. Kaur and V. Sulochana. Crosstalk Minimization in VLSI Interconnects. International Journal of Reconfigurable and Embedded Systems (IJRES). 2013; 2(2): 89-98.

[5] P. Dong, W. Qian, S. Liao, H. Liang, C. Kung, and N. Feng. Low Loss Silicon Waveguides for Application of Optical Interconnects. Proc. of IEEE Photonics Society Summer Topicals. 2010: 191-192.

[6] J. Fujukata, K. Nishi, A. Gomyo, J. Ushida, T. Ishi, H. Yukawa, D. Okamoto, M. Nakada, T. Shimizu, M. Kinoshita, K. Nose, M. Nakada, T. Shimizu, M. Kinoshita, K. Nose, M. Mizuno, T. Tsuchizawa, T. Watanabe, K. Yamada, S. Itabashi, and K. Ohashi. LSI On-Chip Optical Interconnection with Si Nano-Photonics. IEICE Transaction Electron. 2008; E91-C(2): 131-137.

[7] B.D.A.B. Miller. Device Requirements for Optical Interconnects to Silicon Chips. Proc. of the IEEE. 2009; 97(7): 1166-1185.

[8] G. Chen, H. Chen, M. Haurylau, N.A. Nelson, D.H. Albonesi, P.M. Fauchet, and E.G. Friedman. On-chip copperbased vs. optical interconnects: Delay uncertainty, latency, power, and bandwidth density comparative predictions. International Interconnect Technololgy. Conference (IITC). 2006: 39-41.

[9] G. Chen, H. Chen, M. Haurylau, N. Nelson, D. Albonesi, P. M. Fauchet, and E. G. Friedman. Electrical and optical on-chip interconnects in scaled microprocessors. Proc. of the IEEE Int. Symp. Circuits Syst. 2005; 3: 2514-2517.

[10] J. Chen, N. Bamiedakis, P.P. Vasil, T.J. Edwards, C.T.A. Brown, R.V Penty, and I.H. White. High-Bandwidth and Large Coupling Tolerance Graded-Index Multimode Polymer Waveguides for On-Board High-Speed Optical Interconnects. Journal of Lightwave Technology. 2016; 34(12): 2934-2940.

[11] P.K. Shen, A. Hosseini, X. Xu, Y. Hei, Z. Pan, and R.T. Chen. Multiple-Input Multiple-Output Enabled Large Bandwidth Density On-Chip Optical Interconnect. Journal of Lightwave Technology, 2016; 34(12): 2969-2974.

[12] J.W. Goodman, F.J. Leonberger, S.Y. Kung and R.A. Athale. Optical Interconnections for VLSI. Proc. of the IEEE. 1984; 72(7): 850-866.

[13] K. Nieweglowski and K.J. Wolter. Optical Analysis of Short-Distance Optical Interconnect on the PCB-Level. in Electronics Systemitegration Technology Conference, Dresden, Germany. 2006; 1: 392-397.

[14] M.K.S.S. Saini. All-optical logic gate in silicon nanowire optical waveguides. IET Circuits Devices System. 2011; 5(2): $115-122$.

[15] H. Huang, K. Liu, B. Qi, and V. J. Sorger. Re-analysis of single-mode conditions for Silicon rib waveguides at $1550 \mathrm{~nm}$ wavelength. Journal of Lightwave Technology. 2016; 34(16): 3811-3817.

[16] J. Lousteau, D. Furniss, A.B. Seddon, T.M. Benson, S. Member, A. Vukovic, and P. Sewell, "The Single-Mode Condition for Silicon-on-Insulator Optical Rib Waveguides with Large Cross Section. Journal of Lightwave. 2004; 22(8): 1923-1929.

[17] S.S.M. Sallah, S.H.M. Ali, P.S. Menon, N. Juhari, M.S. Islam, and S.A. Ahmad. Investigation on Optical Interconnect (OI) Link Performance using External Modulator. Proc. of IEEE Regional Sysmposium on Micro and Nanaoelectronics (RSM). 2015: 1-4.

[18] S.S.M. Sallah, S.H.M. Ali, P.S. Menon, N. Juhari and M. S. Islam. Delay Analysis in Symmetrical SOI-Based Rib Waveguide for High Speed Optical Interconnect. in IEEE $6^{\text {th }}$ International Conference on Photonics (ICP) . 2016: $1-3$. 


\section{BIOGRAPHIES OF AUTHORS}

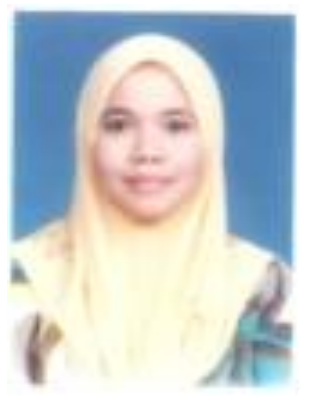

Siti Sarah Binti Md Sallah obtained her B.Eng. Tech. (Electronics) from Universiti Kuala Lumpur-British Malaysian Institute (UniKL-BMI) in 2009 and M.Sc in Microelectronic from University Kebangsaan Malaysia (UKM) in 2012. She is currently pursuing a $\mathrm{PhD}$ degree at MINES Lab, IMEN, UKM. Her research interests revolve around the analog/digital/mixed signal VLSI circuit, design and characterization of SOI based optical waveguide for the application in Optical Interconnect Link.

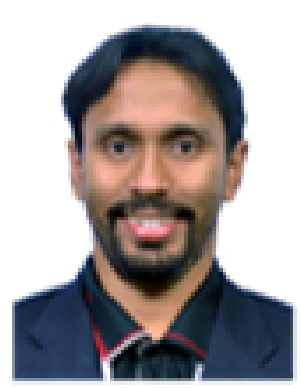

Sawal Hamid Md Ali received his B. Sc. in Electronic and Computer Engineering from Universiti Putra Malaysia (UPM) in 1998 and M.Sc Microelectronic System Design from University of Southampton, United Kingdom in 2004. He obtained a Ph. D in Analog Mixed Signal from University of Southampton, UK in 2009. His specialized field are in analog mixed signal design, VLSI integrated circuit design, FPGA design, ASIC and SoC Design and Wearable Device.

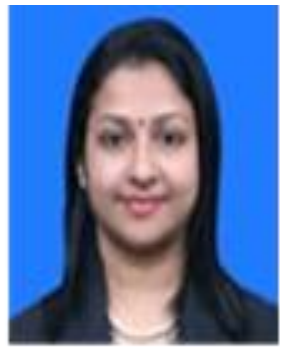

P. Susthitha Menon received her B.Eng. degree in Electrical, Electronics and System Engineering from Universiti Kebangsaan Malaysia (UKM) in 1999 and the M.Sc. degree in optoelectronics from UKM in 2005. She obtained a Ph.D. degree with distinction in Optoelectronics and Nanophotonics from the Institute of Microengineering and Nanoelectronics (IMEN), UKM in 2008. She is currently a senior research fellow at IMEN and her current research interests are in the field of nanophotonic optical waveguides, surface plasmon resonance (SPR), optoelectronics and optical fiber based sensors, which are all geared towards bio-sensing.

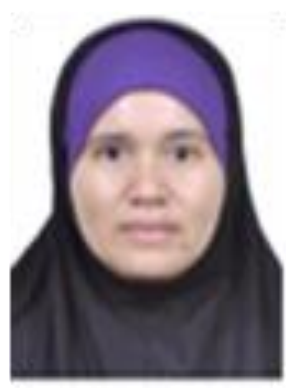

Nurjuliana Binti Juhari obtained her B.Sc and M.Sc from University of Malaya (UM) under the physics department in the years 2003 and 2007. She obtained a PhD degree in Microelectronics from the Institute of Microengineering and Nanoelectronics (IMEN), UKM in 2016. She is currently a lecturer at Universiti Malaysia Perlis (UniMAP) and her research interests revolve around the design, fabrication and characterization of passive devices in submicron level SOI based Arrayed Waveguide Grating (AWG) for the application in CWDM system.

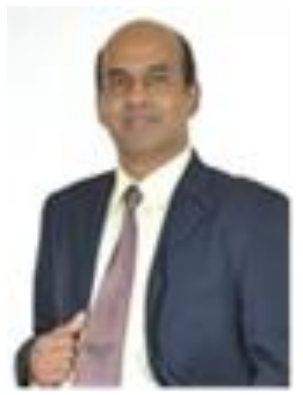

Md. Shabiul Islam received his B. Sc. in Applied Physics \& Electronics in 1985 and the M. Sc. on Application of Microprocessor in Applied Physics \& Electronics in 1986 from University of Rajshahi, Bangladesh. He obtained a Ph.D. on VLSI Design (Digital) in Engineering from Malaysia Multimedia University (MMU) in 2008. He is currently a senior research fellow at Institute of Microengineering \& Nanoelectronics (IMEN) and his current research interests are in the field of Micro/Nano System Design, VLSI Design, Energy Harvesting for Ultra- Low-Power (ULP) Electronic Devices and DSP Hardware Implementation on FPGA using VHDL/Verilog/ DFL Language. 